\title{
The quarter-life crisis? Precarious labour market status and mental health among 25-year-olds in England
}

\author{
Morag Henderson, morag.henderson@ucl.ac.uk \\ UCL Institute of Education, UK
}

\begin{abstract}
Despite an increase in living standards and material comforts in industrialised societies, today's 'emerging adults' (aged from late teens to mid-to-late 20s) face greater challenges than ever before. The aim of this paper is to explore the relationship between labour market status and mental health for the 'millennial generation' in England, and whether it varies by gender and ethnicity. This study will be the first to draw on the results from the 2015 sweep of Next Steps data when the sample members are aged 25 and, together with the previous seven sweeps, bring the debate up to date by providing first estimates of the life condition of contemporary emerging adults. We find black and minority ethnic groups have lower odds of reporting mental ill-health at age 25 than the white group. With respect to labour market status, we find that net of socio-economic characteristics, educational attainment, behavioural variables and income at age 25 , those who are unemployed are more than twice as likely to report symptoms of poor mental health as those who are employed. Shift workers and those on zero-hours contracts are also at a greater risk of mental ill-health by $47 \%$ and $44 \%$ respectively than those who are not shift workers or zero-hours workers. We find no significant difference for those who have a second job or are on a permanent contract for mental health at age 25 compared to those who do not have a second job or are on a temporary contract.
\end{abstract}

Key words Labour market status $\bullet$ mental ill-health $\bullet$ emerging adulthood $\bullet$ millennials $\bullet$ unemployment $\bullet$ zero-hours contracts $\bullet$ shift work

To cite this article: Henderson, M. (2019) The quarter-life crisis? Precarious labour market status and mental health among 25-year-olds in England, Longitudinal and Life Course Studies, vol 10 no 2, 259-276, DOI: 10.1332/175795919X15514456677295

\section{Introduction}

This paper explores the mental health in early adulthood (measured through the reporting of symptoms associated with psychological distress) of men and women born in 1989/90. This 'millennial' generation in England have faced a number of challenges as they entered the world of work: they were aged 18 at the start of the 
Great Recession and faced higher than ever university fees and student loan debt. So much so, the media and popular psychology have described them as confronting a 'Quarter-Life Crisis': 'a crisis that may be experienced in one's twenties, involving anxiety over the direction and quality of one's life' (Collins English Dictionary, 2018).

This paper explores the relationship between mental health in adolescence and early adulthood in order to identify the extent of the anxiety or 'crisis' that this generation may feel. It also examines the links between precarious labour market status and mental health. More specifically, it explores the association between mental health and unemployment, and for those who are employed, whether they are shift workers, have a second job, have a permanent contract or have a zero-hours contract. Data from a large-scale longitudinal study are used to address the following research questions:

1 What is the prevalence, incidence and timing of reporting poor mental health symptoms at ages 14,16 and 25 in England, and how does this vary by ethnicity and gender?

2 Is poor mental health during adolescence associated with poor mental health at age 25 , net of socio-economic status, gender and ethnicity characteristics?

3 How does labour market status vary by ethnicity and gender at age 25?

4 Are precarious labour market relations at age 25 associated with poor mental health at age 25 , net of background characteristics, income and adolescent mental health?

The results reported in this paper extend existing research in a number of ways. First, this paper uses prospective data that explore the adolescent prevalence of mental ill-health and its relationship to outcomes at age 25. This approach avoids retrospective reporting biases and helps to build a deeper understanding of the ways these incidences of poor mental health occur and co-occur from adolescence and early adulthood. Second, the rich data of this cohort study enable us to control for possible confounding characteristics (outlined in the 'Data and methods' section). Third, the unique longitudinal dataset (Next Steps) oversampled black, Asian and minority ethnic (BAME) individuals, which allows the first detailed ethnic comparisons on the mental health and labour market conditions for emerging adults in England in 2015.

\section{Background}

The World Health Organization (WHO) defines mental health as: 'a state of wellbeing in which every individual realizes his or her own potential, can cope with the normal stresses of life, can work productively and fruitfully, and is able to make a contribution to her or his community' (WHO, 2014).

This functionalist interpretation concentrates on a person's potential as well as acknowledging the contribution that a person can make both to work and the wider community. This quote implies what Layard (2013) has made explicit; that there is a cost to society and to the economy of poor mental health. Mental illness has been shown to have a negative impact on a range of domains through the life course including economic activity, relationships and physical health (Copeland et al, 2015) and has been shown to be one of the major causes of life years lost (Murray et al, 2012). 
Mental health is one of our most pervasive public health challenges and is estimated to affect about $25 \%$ of the population in Europe each year (WHO, 2015) and accounts for one fifth of our total disease burden, exceeded only by heart disease (WHO, 2013). Depression and anxiety are the most common causes of mental ill-health and are important contributors to sickness absence from employment (Royal College of Psychiatrists, 2008). A recent report noted that one sixth of the population in England aged 16-64 has a mental health problem (Stevenson and Farmer, 2017). The estimated annual cost to UK economy of poor mental health was put at around $£ 99 \mathrm{bn}$, of which some $\mathcal{K}_{42}$ bn is borne by employers.

Having rich data on several aspects of a person's life, including family background, individual characteristics and behavioural characteristics, and following people over time, is crucial to understanding origins of developmental difficulties and lasting inequalities, in particular mental health. There is extensive evidence that the majority of mental health problems start or are rooted in childhood and that childhood mental health problems cast a long shadow on adult life, for example on education, employment and earnings, physical health, relationship stability and social mobility (Roza et al, 2003; Goodman et al, 2011). Moreover, Ploubidis et al (2017) found that there are higher levels of psychological distress in midlife among British people born in 1970 compared to those born in 1958. Wittchen and Jacobi (2005) suggest that the prevalence of distress has increased over recent decades across a number of European countries.

Minority ethnic groups in England face a number of challenges, for example they have poorer physical health, shorter life expectancies and have particular difficulties in accessing medical advice (National Health Service, 2009). Moreover there is some evidence to suggest that BAME populations in the UK have a higher risk of psychosis (see, for example, Fearon et al, 2006; Kirkbride et al, 2008). More specifically, there is some evidence of an increased risk for psychosis among Black African and Black Caribbean populations in Britain (Fearon et al, 2006) and lower risk among Indian (Cochrane, 1989) and Pakistani populations (King et al, 1994). More recently, analysis using the Adult Psychiatric Morbidity survey found little variation between white, black and South Asian men in the rates of any common mental disorder ${ }^{1}$ (CMD); among women, the South Asian group were at elevated risk of experiencing a CMD (McManus, 2009). However many of these existing studies are small scale or not designed to recruit suitable minority ethnic samples (see Rees, 2016), local studies (for instance, Hatch et al, 2011) with limited ethnic categories (for example, DasMunshi et al, 2012, who make the comparison between white and non-white groups only). A recent systematic review noted: 'there is very little recent information from appropriately designed surveys on the rates of mental health disorders in English populations according to ethnic groupings' (Rees et al, 2016: vi).

This paper describes the longitudinal measures of mental ill-health and their association with labour market status. We identify how precarious these young adults' labour market positions are, including whether they are unemployed or not and, if they are employed, whether they are shift workers, have a second job, have a permanent contract or have a zero-hours contract. These measures are frequently used to study the scale of inequalities between different groups within the labour market and offer a deeper contextual understanding than income (Annual Population Survey, 2018). We briefly define these labour market distinctions and offer some insight in relation to mental health using previous literature. 
For the purpose of this paper, unemployment is defined as a situation where someone is of working age but not working and that they are not in full-time education, training, apprenticeships, full- or part-time employment, looking after the home, voluntary work (unpaid) or long-term sick or disabled. Previous work has shown that those who are unemployed show more psychological distress than employed people (see, for example, Paul and Moser, 2009). Some mechanisms offered to explain the association between unemployment and mental ill-health are that the unemployed have less structured time, fewer opportunities for social engagement, a lack of purpose, low status and an absence of activity (Jahoda, 1981, 1982). Previous research has shown that when those who were unemployed find a job their mental health improves significantly (McKee-Ryan et al, 2005), which suggests a causal relationship. However there remains a possibility that a person's labour market status is a consequence of mental health problems: those who have such problems have been shown to be more likely to lose their jobs, and need more time to find employment (Winefield, 1995; Mastekaasa, 1996).

Shift work comprises recurring periods in which different groups of workers do the same jobs in relay, often involving variable hours or night shifts. It can encompass aspects of service and manufacturing jobs but may also capture people in public services such as police officers and medical staff. The evidence on shift work is suggestive of an adverse effect on mental and physical health (Bara and Arber, 2009; Driesen et al, 2011), however Harrington (2001) notes that isolating the 'effect' of shift work on mental health is difficult as there may be endogenous effects from selection and additional (unobserved) stressors other than shift work itself.

Job insecurity applies to people who fear they might lose their job(s) and has been associated with a reduction in psychological well-being (De Witte, 1999). The following three measures of labour market status capture aspects of job insecurity. A second job is a role that someone takes on in addition to their primary employment. It may be a marker of needing additional funds, a way to acquiring different skills or spreading the risk in case a job is lost. A permanent contract is where both parties agree to do business with each other for an indefinite amount of time; clearly this is the antithesis of job insecurity as there is no fixed-term agreement. A zero-hours contract is the name given to a type of employment contract where the employer has the discretion to vary the employee's working hours, usually anywhere from full-time to 'zero hours'. This is a precarious contract where the employer typically asserts that they have no obligation to provide regular work for the employee. It should be noted that these labour market relations are not mutually exclusive, for example, one may be a shift worker on a permanent contract, but the combination captures dimensions of precarious labour market status.

Clearly, the labour market opportunities available are a signal of the economic health of a country. A discussion of the economic context, relevant to the cohort of interest, follows now.

\section{Data and methods}

Data

Next Steps (formerly known as the Longitudinal Study of Young People in England (LSYPE)) began in 2004 when the sample members were aged between 13 and 14 years. The participants (born in 1989/90) were followed annually by the Department for Education until they were aged 20, resulting in seven waves of data. The original 
sampling frame was a two-stage probability sample, adopted where schools were the primary sampling unit (including maintained, independent and pupil referral unit schools) with students born between 1 September 1989 and 31 August 1990 randomly selected within each school. Schools in deprived areas were oversampled and so too were ethnic minorities to achieve target numbers of 1,000 pupils in each group (DfE, 2011). In 2013 the Centre for Longitudinal Studies (CLS) was funded by the Economic and Social Research Council (ESRC) to restart the study and follow up participants at age 25 , with the plan to continue data collection throughout their adult lives. This plugs the data gap between the British Cohort Study (participants born in 1970) and Millennium Cohort Study (participants born in 2001) in the UK.

The most recent Next Steps data collection took place in 2015 when the study members were aged 25 , with an overall response rate among eligible cohort members of $51 \%$ of the issued sample (Calderwood, 2018). For the purpose of this analysis, the sample consists of those who took part in the eighth sweep of data $(\mathrm{N}=7,707)$ providing data on their 'emerging adulthood' (Arnett, 2007). The unemployment rate of the Next Steps sample is 6\% in 2015, consistent with the 5\% reported in the Labour Force Survey for the 25-34 age group in 2015 (Figure 1).

The Great Recession, which began in 2008 when the Next Steps cohort were aged 18/19, was the deepest UK recession since the Second World War and devastated the global economy. The recession lasted 1.25 years; however, many of the effects lasted long after it ended, including reduced job opportunities and insecure contracts (Schoon and Bynner, this issue).

Figure 1 shows the unemployment trends by age in the UK from 1992 to 2018 reported in the ONS Labour Force Survey. The graph indicates those aged 16/17 were at higher risk of unemployment than those aged 18-24 and 25-35 among the economically advantaged in the years after the Great Recession. For those aged 25-34, the unemployment rate went from $7.4 \%$ in 2009 to $5.0 \%$ in 2015 , peaking at $7.9 \%$ in 2011. The graph also shows that the period after the Great Recession saw higher

Figure 1: Unemployment rates: UK, 1992-2018.

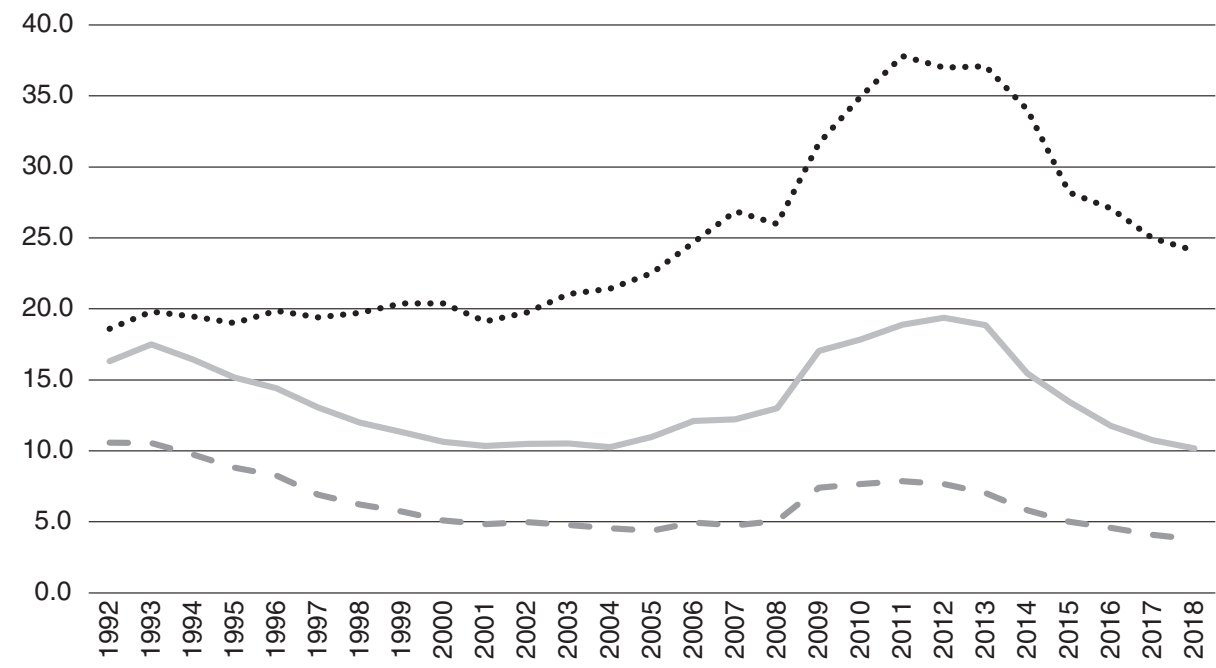

Source: ONS Labour Force Survey. 
unemployment rates, compared to the period after the 1990s recession, for the age groups under 25. In addition, the unemployment rate of the 25-34 age group had been higher in the 1990s, in the region of 10\%. The publicly available time-series data does not encompass the early-1980s recession; however, the National Child Development Study recorded an unemployment rate of $4.61 \%(\mathrm{~N}=11,356)$ for those aged 23 in 1981. Taken together, these results indicate that the Next Steps cohort had faced exceptionally challenging labour market conditions in their early twenties. However, care must be taken in interpreting these results as there are many factors that may influence unemployment rates over time, including the age composition of the population of economically active groups (Barwell, 2000); compulsory school leaving age; structural changes in the labour market and the nature of the skills demanded by the labour market.

Our main outcome of interest is the response to the short-form versions of the General Health Questionnaire (GHQ-12), a screening device for identifying minor psychiatric disorders in the general population and within non-psychiatric clinical settings (such as primary care or out-patient care) (Goldberg and Williams, 1988). It concentrates on psychological ill-health, as well as general levels of happiness, depression and self-confidence. This is a validated tool that is suitable for all ages from adolescence upwards (Werneke et al, 2000). It is a battery of 12 statements that assesses the respondent's current state and asks if that differs from his or her usual state. Because of this design, one of the limitations is that it is sensitive to short-term psychiatric disorders but not to long-standing characteristics of the respondent. The self-administered items focus on two areas: the ability to function normally and the appearance of new phenomena. Cohort members were given a list of 12 questions: 'Have you: been able to concentrate on what you are doing; lost sleep over worry; been playing a useful part in things; been capable of making decisions; been constantly under strain; been unable to overcome difficulties; enjoyed day-to-day activities; been able to face up to problems; been unhappy or depressed; been losing confidence in self; been thinking of yourself as a worthless person; been reasonably happy?' They were asked to rate how often they experienced each symptom on a four-point scale to indicate if they are at present: 'not at all', 'no more than usual', 'rather more than usual' or 'much more than usual'. Those who said they experienced a symptom 'not at all' or 'no more than usual' were given a score of zero. Those who said they experienced a symptom more or much more than usual were given a score of one. Cohort members were grouped into two categories, those with no evidence of psychological disturbance or mental ill-health (a score of $0-3$ out of 12); and those showing signs of probable psychological disturbance or mental ill-health (a score of 4 or more). Goldberg et al (1998) suggest that the mean GHQ-12 score in the population should act as the threshold of identifying 'cases' of mental illness (probable psychiatric illness); however, this threshold is quite low in Next Steps (mean=2.21), which may lead to a high level of false positives. Therefore we use the ' 4 or more' threshold, which is the same as the threshold used on surveys among similar populations to enable comparability (Health Survey for England, 2016, for example). GHQ-12 is captured at age 14, 16 and age 25 in Next Steps. At age 25, 7,363 Next Steps cohort members completed the General Health Questionnaire (GHQ-12).

We make use of the first four waves of Next Steps to capture the main independent variables: parental social class measured by taking the highest class category mentioned 
from age $13-16,{ }^{2}$ equivalised permanent income, ${ }^{3}$ housing tenure measured by taking the highest tenure reported at age 13 and $14,{ }^{4}$ ethnicity, ${ }^{5}$ gender and capped linear GCSE scores. ${ }^{6}$ We also include measures taken at age 25 about whether they have achieved a degree from an accredited institution. At age 25 we can identify the participants' labour market situations, more specifically whether they report being unemployed; and for those who are employed, whether they are shift workers, have a second job, have a permanent contract or have a zero-hours contract. The relevant questions asked in the survey are:

- 'Which of the following describes what you spend most time doing? Employee - in paid work; in unpaid voluntary work; Unemployed; Education: School/ college/university; Apprenticeship; On a government scheme for employment training; Sick or disabled; Looking after home or family; or Something else.'

- 'We are now going to ask you some questions about your current job: Does your main job involve shift work?'; 'We have collected details about your main job: Do you have a second job?'; 'Leaving aside your own personal intentions and circumstances, is your job a permanent job or is there some way in which it is not permanent?'; and 'In your main job, do you have a zero-hours contract?'

We exclude from the analysis the 822 cohort members who are in full-time education, family carers, in an apprenticeship, in a government training scheme, undertaking unpaid voluntary work, or sick or disabled at age 25.

As with all longitudinal surveys, Next Steps suffers from attrition, as documented in Calderwood (2018). Some form of compensation is needed to reduce the biases in survey estimates resulting from missing data and to account for this, weighting adjustments and imputation is used. Observations are included in the analytic models when the dependent variable responses have no missing data and for the purpose of the descriptive statistics the completed cases are presented. However, some independent variables also suffer from item non-response. To reduce potential bias from item-missing data, we used multiple imputation procedures (Johnson and Young, 2011) in STATA 15 to create 20 complete data sets using chained regressions to impute values for missing data on the predictor variables. Then, following Rubin (1987) the estimates were combined across the 20 imputed data sets and all estimates were weighted using the age 25 attrition weights following the recommendations of Calderwood (2018). The main advantages of this approach are avoiding the loss of statistical power due to reduced $\mathrm{N}$ and reducing attrition and sampling bias.

\section{Modelling strategy}

Regression analyses were used to address the research questions about how adolescent mental health is associated with adult mental health at age 25. For the binary outcome, adult mental health, we run logistic regressions and report odds ratios with statistical significance, which represent the risk associated with a one-unit increase in the independent variables. The base models include gender, ethnicity, social class of parents, housing tenure during adolescence, equivalised household income during adolescence and educational attainment as covariates. We additionally control for degree attainment and income at age 25 when predicting mental health at age 25 . 


\section{Results}

1. What is the prevalence, incidence and timing of mental ill-health at ages 14, 16 and 25 in England, and how does this vary by ethnicity and gender?

We explore the cross-sectional relationship of symptoms of mental ill-health from adolescence to early adulthood by gender and ethnicity in Table 1. Overall, around one in five report mental ill-health at age 14 and closer to one in four report mental ill-health at age 16 and 25. The results show an increase in symptoms of mental ill-health from age 14 to 16 for both men and women. From age 16 to 25 there is an increase in the proportion of men reporting mental ill-health by around four percentage points and a reduction in the proportion of women reporting mental ill-health by three percentage points. Mental health incidences by ethnicity are also presented in Table 1. The results show that at all three time points the highest proportion of cohort members with 'Mixed' and 'Other' ethnic identities describe mental ill-health symptoms. The lowest proportions reporting mental ill-health symptoms at 14 and 25 are for Indian and Pakistani, also among the lowest at age 16.

In terms of the frequency of reported symptoms of mental ill-health, shown in Table 2, we find that more than half of the sample (58\%) experiences no mental illhealth over time while $28 \%$ experience one incidence of mental ill-health, $11 \%$ two and 3\% at all time points. A higher proportion of women report mental ill-health symptoms once, twice or all waves, compared to men. The descriptive statistics show that Indian, Pakistani, Bangladeshi, Black Caribbean and African cohort members are more likely to have zero incidence of mental ill-health. The correlation of mental ill-health across all ages is quite low (Table 3), with age 14 and age 25 mental illhealth correlated at 0.28 , age 16 and 25 correlated at 0.34 . The strongest correlation is between mental health measures at age 14 and 16, the closest age proximity at 0.48 . Including these three mental health measures in a Principal Component Analysis identifies only one component with an Eigenvalue of greater than one (1.42), which means the data requires only one factor to describe it. This suggests some stability in the underlying nature of the mental health incidence over time.

Table 1: Experiencing mental ill-health, by ethnicity and gender (\%)

\begin{tabular}{|l|c|c|c|c|}
\hline & $\begin{array}{c}\text { Next Steps } \\
\text { Sample }\end{array}$ & $\begin{array}{c}\text { Mental health issues } \\
\text { at age } \mathbf{1 4}\end{array}$ & $\begin{array}{c}\text { Mental health issues } \\
\text { at age 16 }\end{array}$ & $\begin{array}{c}\text { Mental health } \\
\text { issues at age 25 }\end{array}$ \\
\hline White & 84 & 19 & 23 & 24 \\
\hline Mixed & 3 & 27 & 27 & 26 \\
\hline Indian & 2 & 13 & 23 & 20 \\
\hline Pakistani & 3 & 18 & 23 & 21 \\
\hline Bangladeshi & 1 & 18 & 25 & 22 \\
\hline Black Caribbean & 2 & 21 & 22 & 27 \\
\hline Black African & 2 & 22 & 30 & 22 \\
\hline Other & 3 & 27 & 34 & 29 \\
\hline Male & 49 & 12 & 17 & 21 \\
\hline Female & 51 & 25 & 29 & 26 \\
\hline Total (\%) & & $\mathbf{1 9}$ & $\mathbf{2 3}$ & $\mathbf{2 4}$ \\
\hline
\end{tabular}

$\mathrm{N}=7,363$ : those who answered all mental health questions at three time points. 
Table 2: Frequency of experiencing mental ill-health over time, by ethnicity and gender (\%)

\begin{tabular}{|l|c|c|c|c|c|}
\hline & Zero & Once & Twice & All waves & Total \\
\hline White & 57 & 29 & 11 & 3 & 100 \\
\hline Mixed & 50 & 34 & 12 & 3 & 100 \\
\hline Indian & 64 & 26 & 7 & 3 & 100 \\
\hline Pakistani & 62 & 24 & 11 & 3 & 100 \\
\hline Bangladeshi & 61 & 25 & 11 & 2 & 100 \\
\hline Black Caribbean & 60 & 26 & 10 & 4 & 100 \\
\hline Black African & 63 & 21 & 13 & 3 & 100 \\
\hline Other & 52 & 23 & 21 & 5 & 100 \\
\hline Male & 65 & 25 & 8 & 2 & 100 \\
\hline Female & 52 & 30 & 14 & 5 & 100 \\
\hline Total (\%) & $\mathbf{5 8}$ & $\mathbf{2 8}$ & $\mathbf{1 1}$ & $\mathbf{3}$ & $\mathbf{1 0 0}$ \\
\hline
\end{tabular}

$\mathrm{N}=7,363$ : those who answered all mental health questions at three time points.

Table 3: Tetrachoric correlation, mental ill-health at all ages

\begin{tabular}{|l|l|l|c|}
\hline & Age 25 & Age 16 & Age 14 \\
\hline Age 25 & 1 & & \\
\hline Age 16 & 0.34 & 1 & 1 \\
\hline Age 14 & 0.28 & 0.48 & \\
\hline
\end{tabular}

$\mathrm{N}=7,363$ : those who answered all mental health questions at three time points.

\section{Is mental ill-health during adolescence associated with mental ill-health at age 25,} net of socio-economic status, gender and ethnicity characteristics?

In order to explore mental health over the course of time, symptoms of mental ill-health expressed at age 14 and at 16 are included in the models predicting mental health at age 25. The results in Table 4 (Model 1) show that those who had symptoms of mental ill-health at ages 14 or 16 have increased odds of having mental ill-health at age 25; these are significant net of each other. These adolescent mental health measures are significant even once ethnicity, gender, class, housing tenure and income are taken into account (Model 2) and once educational attainment is added (Model 3). This means that people who had mental health problems at age 16 have more than twice the odds of reporting mental ill-health at age 25 (OR 2.44, <0.001) and reporting symptoms at age 14 is associated with an increased odds of reporting mental ill-health at age 25 (OR 1.72, <0.001), net of socio-demographic characteristics and education.

Model 3 reveals some interesting associations, for example, women have higher odds of reporting mental ill-health at age 25 than men; however, this is only marginally significant. Moreover, those who are Indian, Pakistani, Bangladeshi and Black African have statistically significantly lower odds of reporting mental ill-health at age 25 than those who are white, net of socio-economic status and education. With respect to socio-economic background, those who lived in rented accommodation during adolescence have higher odds of reporting mental ill-health, and those who come from wealthier backgrounds have lower odds of reporting mental ill-health; class does not yield any independently statistically significant results. GCSE attainment is not predictive of mental ill-health at age 25, and degree achievement has a marginally significantly association with increased odds of having symptoms of mental ill-health. 
Table 4: Logistic regression predicting adult mental ill-health

\begin{tabular}{|c|c|c|c|c|c|c|}
\hline & \multicolumn{2}{|c|}{ Model 1} & \multicolumn{2}{|c|}{ Model 2} & \multicolumn{2}{|c|}{ Model 3} \\
\hline & OR & (SE) & $\mathrm{OR}$ & (SE) & $\mathrm{OR}$ & (SE) \\
\hline Mental ill-health age 16 & $2.43 * * *$ & $(0.16)$ & $2.43 * * *$ & $(0.17)$ & $2.44 * * *$ & $(0.17)$ \\
\hline Mental ill-health age 14 & $1.77 * * *$ & $(0.12)$ & $1.73 * * *$ & $(0.12)$ & $1.72^{* * * *}$ & $(0.12)$ \\
\hline \multicolumn{7}{|l|}{ Ref: Male } \\
\hline Female & & & $1.10+$ & (0.06) & $1.11+$ & $(0.07)$ \\
\hline \multicolumn{7}{|l|}{ Ref: White } \\
\hline Mixed & & & 0.94 & $(0.12)$ & 0.94 & $(0.13)$ \\
\hline Indian & & & $0.77 *$ & $(0.10)$ & $0.76 *$ & $(0.10)$ \\
\hline Pakistani & & & $0.76 *$ & $(0.10)$ & $0.74 *$ & $(0.10)$ \\
\hline Bangladeshi & & & $0.72 *$ & $(0.10)$ & $0.72 *$ & $(0.10)$ \\
\hline Black Caribbean & & & 1.08 & $(0.17)$ & 1.06 & $(0.16)$ \\
\hline Black African & & & $0.70 *$ & $(0.10)$ & $0.68 *$ & $(0.10)$ \\
\hline Other & & & 1.03 & $(0.15)$ & 1.03 & $(0.15)$ \\
\hline \multicolumn{7}{|l|}{ Ref: Higher managerial } \\
\hline Intermediate & & & 0.99 & $(0.08)$ & 0.98 & $(0.08)$ \\
\hline Routine & & & 1.04 & $(0.08)$ & 1.02 & $(0.08)$ \\
\hline \multicolumn{7}{|l|}{ Ref: Owns/mortgage } \\
\hline Rent/Other & & & $1.21 * *$ & $(0.08)$ & $1.19 *$ & $(0.08)$ \\
\hline Equivalised household income 13-16 & & & $0.93^{*}$ & $(0.03)$ & $0.94 *$ & $(0.03)$ \\
\hline Capped linear GCSE score & & & & & $1.00 *$ & $(0.00)$ \\
\hline \multicolumn{7}{|l|}{ Ref: No university degree } \\
\hline University degree & & & & & $1.13+$ & $(0.08)$ \\
\hline Constant & $0.21 * * *$ & $(0.01)$ & $0.22 * * *$ & $(0.02)$ & $0.27^{* * *}$ & $(0.04)$ \\
\hline Adjusted $\mathrm{R}^{2}$ & \multicolumn{2}{|c|}{0.05} & \multicolumn{2}{|c|}{0.06} & \multicolumn{2}{|c|}{0.06} \\
\hline Observations & \multicolumn{2}{|c|}{7,363} & \multicolumn{2}{|c|}{7,363} & \multicolumn{2}{|c|}{7,363} \\
\hline
\end{tabular}

*** $p<0.001, * * p<0.01, * p<0.05,+p<0.10$.

\section{How does labour market status vary by ethnicity and gender at age 25?}

Table 5 shows that a higher proportion of men compared to women are unemployed at age 25 (excluding those who are in full-time education, family carers, on apprenticeships, in government training programmes or sick or disabled). Just over one fifth of 25-year-olds in the labour force are shift workers with no difference by gender. With respect to having a second job, a slightly higher proportion of women $(7 \%)$ compared to men (5\%) have a main job and a second job. There are no gender differences for those with permanent contracts and a slightly higher proportion of men $(7 \%)$ have a zero-hours contract compared to women $(5 \%)$.

With respect to the labour market status by ethnicity (Table 6) the highest proportion unemployed is among young Pakistanis of working age, and a higher proportion of all black and minority ethnic groups are unemployed compared to the white group. The high proportions of Black African (26\%), Pakistani (27\%) and Black Caribbean (24\%) are shift workers. While having a permanent contract is the norm, the lowest proportions to have one are among Black African (80\%) and Other (81\%). For those on zero-hours contracts there is also some variation by ethnicity: those who are of Mixed ethnicity (10\%), Pakistani (10\%), Black African 
Table 5: Labour market status at age 25 by gender

\begin{tabular}{|l|c|c|c|c|}
\hline & Male (\%) & Female (\%) & Total (\%) & N \\
\hline Unemployed & 7 & 5 & 6 & 6,885 \\
\hline Shift worker & 22 & 22 & 22 & 6,453 \\
\hline Second job & 5 & 7 & 6 & 6,453 \\
\hline Permanent contract & 90 & 89 & 89 & 6,453 \\
\hline Zero-hours contract & 7 & 5 & 6 & 6,453 \\
\hline
\end{tabular}

Excluding the economically inactive: in full-time education, training, apprenticeships, looking after the home, voluntary work (unpaid) or long-term sick or disabled.

(9\%), Other (8\%), Black Caribbean (7\%), Indian (6\%) and White (5\%) have zerohours contracts.

These descriptive relationships are tested in multiple logistic regression models presented in Table 7. These models take into account socio-economic characteristics and educational attainment. The results show that women have statistically significant lower odds of being unemployed (OR $0.80, p<0.05)$ and having a zero-hours contract (OR $0.73, p<0.01$ ) than men, net of family background and educational attainment, but women have higher odds of having a second job (OR 1.30, $p<0.05)$ than men. There is no statistically significant difference between men and women for shift work or permanent contracts.

There is evidence of ethnic variation in labour market status at age 25. More specifically, compared to the white group, those who identify as being mixed race have statistically significant higher odds of being unemployed (OR 1.73, $p<0.05$ ), so too do those who are Pakistani (OR 1.94, $p<0.001$ ), Black African (OR 1.89, $p$ $<0.01)$ and 'Other' (OR 1.98, $p<0.01)$. With respect to shift work, those who are Pakistani and Black African have higher odds of being shift workers (1.30, $p<0.05$ and 1.41, $p<0.05$ respectively) compared to the white group, and Bangladeshis have lower odds $(0.72, p<0.05)$. The only ethnic variation identified for having a second job is found for those who are Black Caribbean, who have higher odds $(1.77, p<0.05)$ of having a second job compared to the white group. The evidence from Table 7 , Model 4 suggests that there is some variation by ethnicity for having a permanent contract. Those who are Pakistani, Black African and Other have lower odds of having a permanent contract than the white group (OR 0.65, $p<0.05$; OR 0.52, $p<0.001$; and $\mathrm{OR} 0.51, p<0.001$ respectively) even when education and socioeconomic background characteristics are taken into account. Mixed race, Pakistani, Black African and 'Other' ethnic groups all have higher odds, net of social background characteristics, of having a zero-hours contract compared to the white group.

\section{Are precarious labour market relations at age 25 associated with poor mental health} at age 25, net of background characteristics, income and adolescent mental health?

Table 8 (Models 1-5) takes the base model used in Table 7, Model 3, and includes labour market statuses individually to examine their association with mental ill-health at age 25 , taking into account socio-demographic characteristics, degree attainment and income at age 25 . The results show that those who are unemployed have almost three times the odds of reporting mental ill-health (OR 2.83, p <0.001); shift work is associated with an increased odds of having poor mental health (OR 1.47, $p<0.001)$ and having a zero-hours contract is associated with a greater chance of 

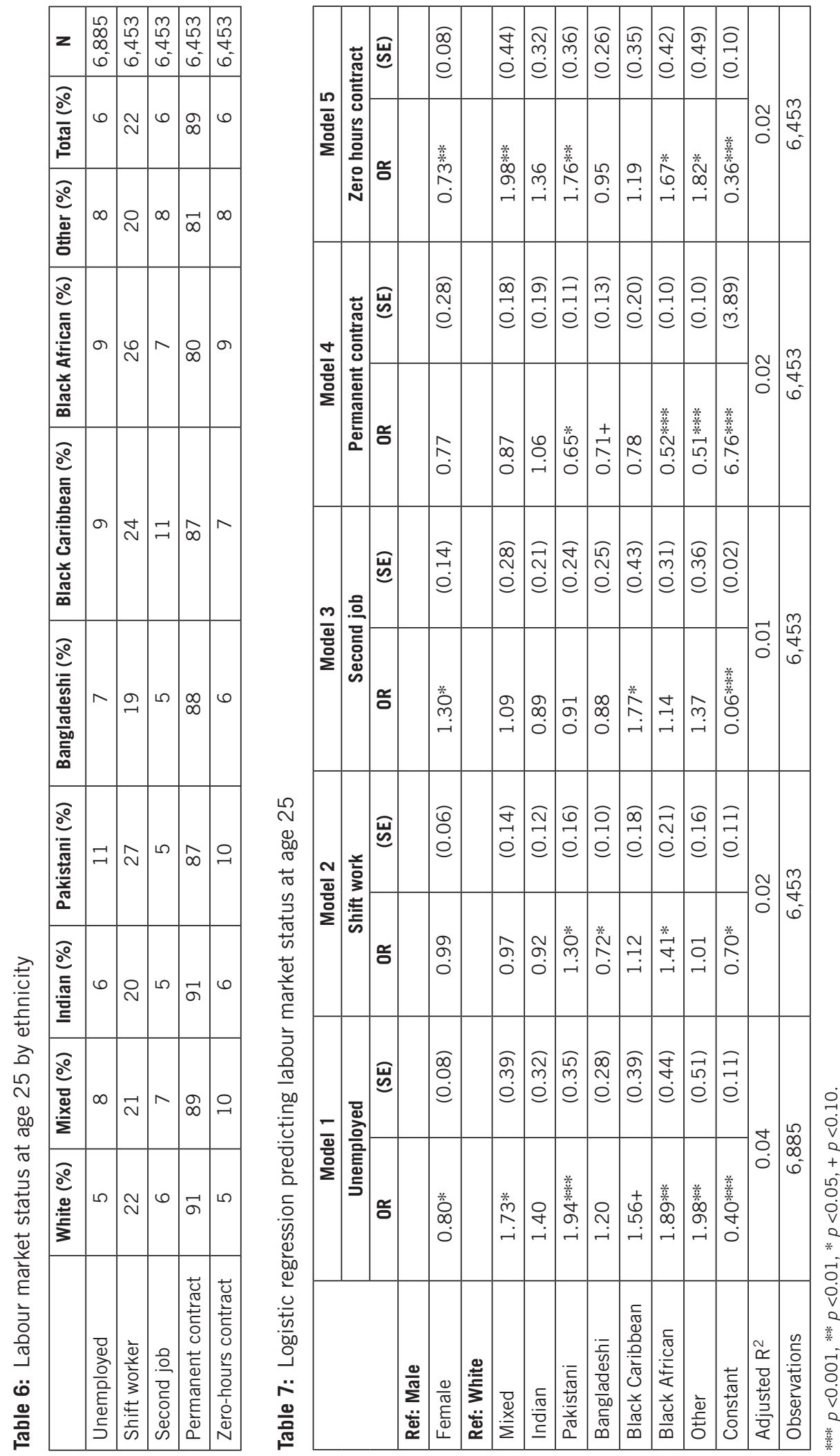

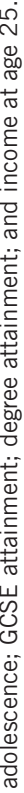
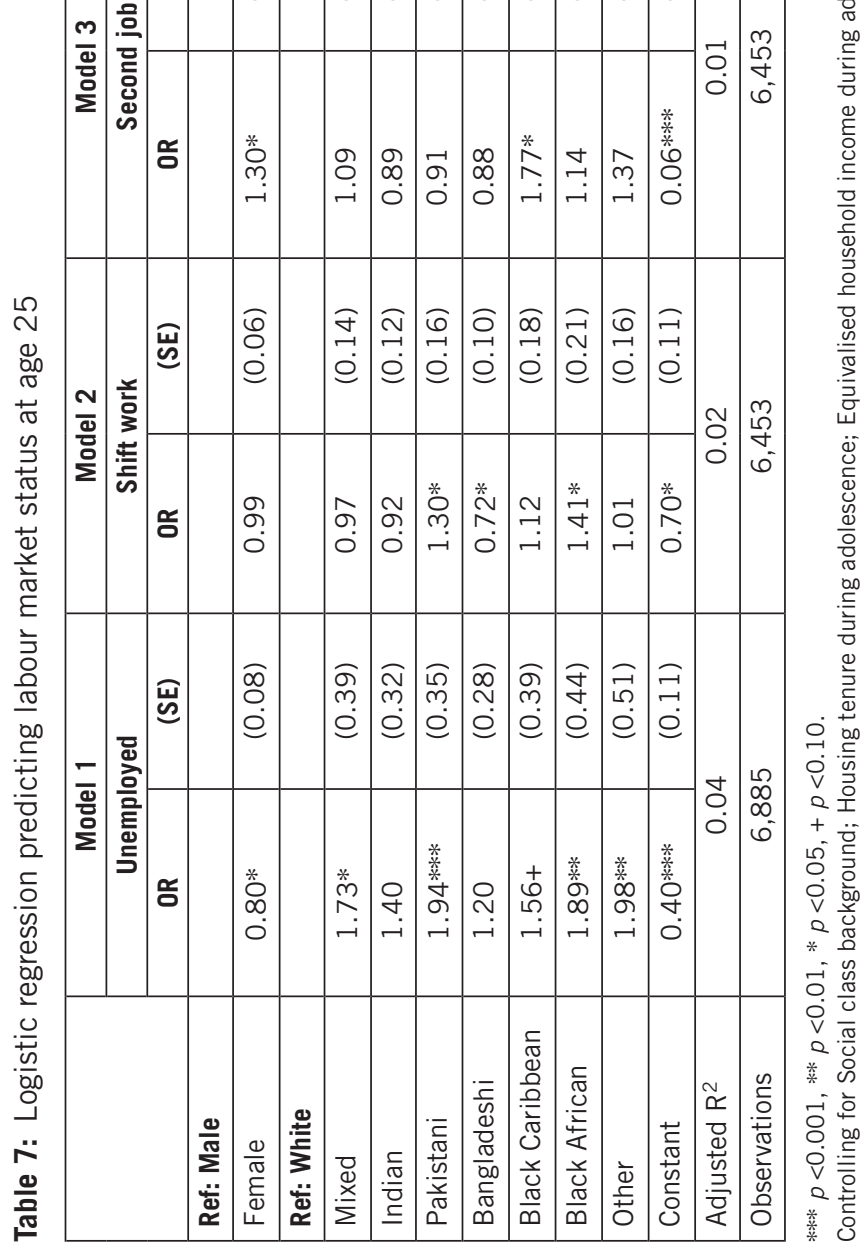


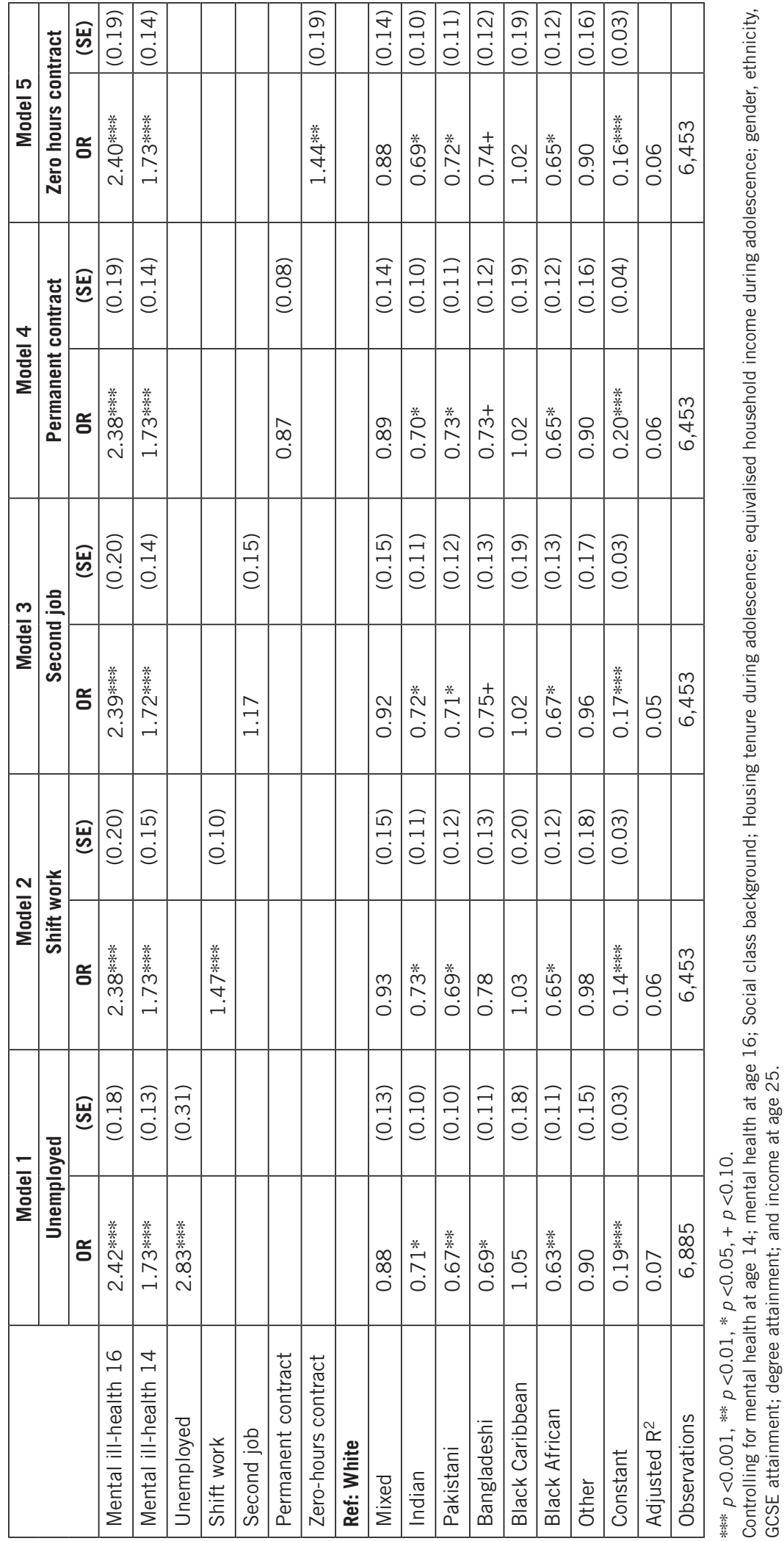


having mental ill-health at age 25 (OR 1.44, $p<0.01$ ). There is no evidence that having a second job or having a permanent contract is significantly associated with mental ill-health. These results are robust to tests using different GHQ symptom thresholds, for example those who report two or more symptoms of mental ill-health, four or more, six or more and eight or more. The ethnicity covariates remain relatively stable across these models, and reveal that compared to white groups, Indian, Pakistani and Black Africans have statistically lower odds of reporting mental ill-health at age 25 .

\section{Discussion}

In the period after the Great Recession the labour market become a more precarious place, with a rise in unemployment and a shift towards a 'gig economy', where temporary contracts and zero-hours contracts became the norm (Schoon and Bynner, this issue). This article examined evidence from a longitudinal study of young adults who were aged 25 in 2015 and who entered the labour market in the wake of the 2008 financial crisis and, as a result, faced precarious employment opportunities.

There are a number of limitations of the present analysis, which should be noted. First, the analysis in this paper is not a direct test of an 'effect' of the Great Recession on labour market outcomes and mental ill-health, instead the economic context was discussed so that some inference can be drawn. The Next Steps data is used separately to examine the association between labour market relationships and mental ill-health. Second, despite controlling for much of the rich background data available in Next Steps, this analysis may be biased by the omission of other variables, which may influence both employment status and mental health, therefore creating a spurious correlation. Thus these results cannot be interpreted as truly causal, but rather as capturing conditional relationships between background, adolescent mental health, labour market status and adult mental ill-health. Third, as already noted, the GHQ measure captures short-term psychiatric disorders and may not pick-up on long-standing psychiatric issues (such as psychoses), therefore these results may mask some underreported issues among the population.

The results presented in this paper indicate that adolescent mental ill-health is associated with increased risk of having mental ill-health at age 25, net of socioeconomic characteristics and education. This finding suggests that early intervention and continued investment in mental health services for young people is important for alleviating later strain on mental health services. Moreover we find that Indian, Pakistani, Bangladeshi and Black African cohort members have a lower risk of mental ill-health at age 25 compared to the white group (despite facing some of the most challenging labour market conditions). This finding points to either to resilience among these ethnic groups or may suggest some systematic under-reporting of mental health issues among these groups.

We find that being unemployed, a shift worker or on a zero-hours contract is associated with a greater risk of having poor mental ill-health at age 25 . This is consistent with previous research examining the relationship between unemployment and other precarious labour market contracts and mental ill-health outlined in the literature review. Furthermore these results indicate that large economic downturns, such as the Great Recession, may have consequences on not only the financial health but also the mental health of a nation, and interventions should be put in place to support vulnerable groups. These associations may be explained by increased uncertainty, less structured time, low status, a lack of purpose and fewer opportunities 
for social engagement, and points to a Quarter-Life Crisis among this cohort. However a selection effect may be at play, where those with lower mental health may select into precarious jobs, despite having controlled for adolescent mental ill-health.

Moreover the results show that even after taking educational attainment, social class background and gender, there is ethnic variation in labour market status, with Pakistani, Black African and Other groups associated with having higher odds of being unemployed compared to the white group. This may be due to limited job opportunities available to these groups or institutional racism. These findings support previous research that examines ethnic patterns of employment (such as the Annual Population Survey, 2018) and this work extends the literature by looking in more depth at labour market contracts. The evidence presented here also demonstrates that ethnic minorities have more precarious labour market contracts at age 25 . Policy makers should work to ensure that these potentially marginalised groups are reengaged in a stable labour market by building more equality of opportunity. Despite the precariousness of labour market positions, ethnic minorities have lower odds of reporting probably mental ill-health at age 25 .

\section{Notes}

1 Common Mental Disorders include: depression, generalised anxiety disorder, panic disorder, phobias and obsessive compulsive disorder.

2 Social class is measured using the National Statistics Socio-Economic Classification (NSSEC), which uses occupational types to capture dimensions of social class (Rose and Pevalin, 2003). We make use of the three-category NS-SEC, which consists of:Higher Managerial, administrative and professional occupations; Intermediate occupations; Routine and manual occupations. More details can be found at https://www.ons.gov.uk/file?uri=/ methodology/classificationsandstandards/standardoccupationalclassificationsoc/ soc2010/soc2010volume3thenationalstatisticssocioeconomicclassificationnssecrebase donsoc2010/soc2010vol31amendedjanuary2013tcm77179133.pdf.

3 We take an average of the household income over the first four waves and divide by the square root of household size to provide a measure of equivalised permanent income. This has been shown to have a larger effect on young people's educational outcomes than transitory income (Jenkins and Schluter, 2002).

4 This includes whether they rent their home, have a mortgage or own the house outright, capturing aspects of household resource. The highest household resource measured at either age 13 and 14 is used in the models.

5 Ethnicity is self-identified by the cohort member using a 16-category prompt (White British; White Irish; any other White; White and Black Caribbean; White and Black African; White and Asian;Any other mixed background; Indian; Pakistani; Bangladeshi; Any other Asian background; Caribbean; African; Any other Black background; Chinese; any other). These groups are aggregated to enable large enough categories for analysis and the measure used in the analysis is composed by taking the first mention of self-identified ethnic category over the first four waves to reduce missing data.

6 The capped linear GCSE scores are the numeric equivalents of the grades for each subject, summed; taking the grades of the best eight subjects. GCSEs are two-year courses that are taken when an individual is aged 14-16 and are considered Key Stage 4 qualifications. They are subject-specific courses that are assessed by coursework, examination or a combination of both. GCSEs are important as a gateway to study A-level, the traditional academic track post-16. 


\section{References}

Annual Population Survey (2018) 'Unemployment'. Available at: www. ethnicity-facts-figures.service.gov.uk/work-pay-and-benefits/unemployment-andeconomic-inactivity/unemployment/latest.

Arnett, J.J. (2007) 'Emerging adulthood: What is it, and what is it good for?' Child Development Perspectives, 1(2): 68-73. doi: 10.1111/j.1750-8606.2007.00016.x

Bara, A.C. and Arber, S. (2009) 'Working shifts and mental health: Findings from the British Household Panel Survey (1995-2005)', Scandinavian Journal of Work, Environment and Health, 35(5): 361-7. doi: 10.5271/sjweh.1344

Barwell, R. (2000) 'Age structure and the UK unemployment rate', Bank of England Working Paper No. 124, London: Bank of England. doi: 10.2139/ssrn.258022

Calderwood, L. (ed.) (2018) 'Next Steps sweep 8 - Age 25 survey user guide (second edition)'. Institute of Education, University College London. Available at: https:// cls.ucl.ac.uk/wp-content/uploads/2017/11/5545age_25_survey_user_guide-1.pdf.

Cochrane, R. and Bal, S.S. (1989) 'Mental hospital admission rates of immigrants to England: A comparison of 1971 and 1981', Social Psychiatry Epidemiology, 24(1): 2-11. doi: 10.1007/BF01788193

Collins English Dictionary (2018) 'Quarterlife crisis'. Available at: www. collinsdictionary.com/dictionary/english/quarterlife-crisis.

Copeland, W.E., Wolke, D., Shanahan, L. and Costello, E.J. (2015) 'Adult functional outcomes of common childhood psychiatric problems: A prospective, longitudinal study', JAMA Psychiatry, 72(9): 892-9. doi: 10.1001/jamapsychiatry.2015.0730

Das-Munshi,J., Bécares, L., Boydell,J.E., Dewey, M.E., Morgan, C., Stansfeld, S.A. and Prince, M.J. (2012) 'Ethnic density as a buffer for psychotic experiences: Findings from a national survey (EMPIRIC)', British Journal of Psychiatry, 201(4): 282-90. doi: $10.1192 /$ bjp.bp.111.102376

De Witte, H. (1999) 'Job insecurity and psychological well-being: Review of the literature and exploration of some unresolved issues', European Journal of Work and Organizational Psychology, 8(2), 155-77. doi: 10.1080/135943299398302

DfE (Department for Education) (2011) LSYPE user guide to the datasets: Wave 1 to Wave 7, London:Department for Education.Available at: http://doc.ukdataservice. ac.uk/doc/5545/mrdoc/pdf/5545lsype_user_guide_wave_1_to_wave_7.pdf.

Driesen, K., Jansen, N.W., van Amelsvoort, L.G. and Kant, I. (2011) 'The mutual relationship between shift work and depressive complaints: A prospective cohort study', Scandinavian Journal of Work, Environment and Health, 37(5): 402-10. doi: $10.5271 /$ sjweh.3158

Fearon, P., Kirkbride, J.B., Morgan, C., Dazzan, P., Morgan, K., Lloyd, T., Hutchinson, G., Tarrant, J., Fung, W.L., Holloway, J., Mallett, R., Harrison, G., Leff, J., Jones, P.B., Murray, R.M. and AESOP Study Group (2006) 'Incidence of schizophrenia and other psychoses in ethnic minority groups: Results from the MRC AESOP Study', Psychological Medicine, 36(11): 1541-50. doi: 10.1017/ S0033291706008774

Goldberg, D.P. and Williams, P. (1988) A user's guide to the General Health Questionnaire, Basingstoke: NFER-Nelson.

Goldberg, D.P., Oldehinkel, T. and Ormel, J. (1998) 'Why GHQ threshold varies from one place to another', Psychological Medicine, 28(4): 915-21. doi: 10.1017/ S0033291798006874 
Goodman, A., Joyce, R. and Smith, J.P. (2011) 'The long shadow cast by childhood physical and mental problems on adult life', PNAS, 108(15):6032-7. doi:10.1073/ pnas.1016970108

Harrington, J.M. (2001) 'Health effects of shift work and extended hours of work', Occupational and Environmental Medicine, 58(1): 68-72. doi: 10.1136/oem.58.1.68

Hatch, S.L., Frissa, S., Verdecchia, M., Stewart, R., Fear, N.T., Reichenberg, A., Morgan, C., Kankulu, B., Clark, J., Gazard, B., Medcalf, R., the SELCoH Study Team and Hotopf, M. (2011) 'Identifying socio-demographic and socioeconomic determinants of health inequalities in a diverse London community: The South East London Community Health (SELCoH) study', BMC Public Health, 11: 861. doi: 10.1186/1471-2458-11-861

Health Survey for England (2016) 'Health Survey for England 2016: Well-being and mental health'. Leeds: NHS Digital. Available at: http://healthsurvey.hscic.gov.uk/ media/63763/HSE2016-Adult-wel-bei.pdf.

Jahoda, M. (1981) 'Work, employment, and unemployment: Values, theories, and approaches in social research', American Psychologist, 36(2): 184-91. doi: 10.1037/0003-066X.36.2.184

Jahoda, M.(1982) Employment and unemployment, Cambridge: Cambridge University Press. Jenkins, S., and Schluter, C. (2002) 'The Effect of Family Income During Childhood on Later-Life Attainment: Evidence from Germany', No 604, IZA Discussion Papers, Institute for the Study of Labor (IZA), Available at: https://EconPapers. repec.org/RePEc:iza:izadps:dp604.

Johnson, D.R. and Young, R. (2011) 'Toward best practices in analyzing datasets with missing data: Comparisons and recommendations', Journal of Marriage and the Family, 73(5): 926-45. doi: 10.1111/j.1741-3737.2011.00861.x

King, M., Coker, E., Leavey, G., Hoare,A. and Johnson-Sabine, E. (1994) 'Incidence of psychotic illness in London: Comparison of ethnic groups', British Medical Journal, 309(6962): 1115-19. doi: 10.1136/bmj.309.6962.1115

Kirkbride, J.B., Barker, D., Cowden, F., Stamps, R.,Yang, M., Jones, P.B. and Coid, J.W. (2008) 'Psychoses, ethnicity and socio-economic status', British Journal of Psychiatry, 193(1): 18-24. doi: 10.1192/bjp.bp.107.041566

Layard, R. (2013) 'Mental health: The new frontier for labour economics', IZA: Journal of Labor Policy, 2: 2.

Mastekaasa, A. (1996) 'Unemployment and health: Selection effects', Journal of Community \& Applied Social Psychology, 6(3): 189-205. doi: 10.1002/(sici)10991298(199608)6:3\%3C189::aid-casp366\%3E3.3.co;2-f

McKee-Ryan, F., Song, Z., Wanberg, C.R. and Kinicki, A.J. (2005) 'Psychological and physical well-being during unemployment: A meta-analytic study', Journal of Applied Psychology, 90(1): 53-76. doi: 10.1037/0021-9010.90.1.53

McManus, S., Meltzer, H., Brugha, T., Bebbington, P. and Jenkins, R. (eds) (2009) Adult psychiatric morbidity in England, 2007: Results of a household survey, Leeds: NHS Information Centre. Available at: https://files.digital.nhs.uk/publicationimport/ pub02xxx/pub02931/adul-psyc-morb-res-hou-sur-eng-2007-rep.pdf. doi: 10.13140/2.1.1563.5205

Murray, C.J.L., Vos, T., et al (2012) 'Disability-adjusted life years (DALYs) for 291 diseases and injuries in 21 regions, 1990-2010: A systematic analysis for the Global Burden of Disease Study 2010', Lancet, 380: 2197-223. doi: 10.1016/S01406736(12)61689-4 
National Health Service (2009) Black and Minority Ethnic (BME) positive practice guide, London: Department of Health.

Paul, K.I. and Moser, K. (2009) 'Unemployment impairs mental health:Meta-analyses', Journal of Vocational Behaviour, 74(3): 264-82. doi: 10.1016/j.jvb.2009.01.001

Ploubidis, G., Sullivan, A., Brown, M. and Goodman,A. (2017) 'Psychological distress in mid-life: Evidence from the 1958 and 1970 British birth cohorts', Psychological Medicine, 47(2): 291-303. doi: 10.1017/S0033291716002464

Rees, R., Stokes, G., Stansfield, C., Oliver, E., Kneale, D. and Thomas, J. (2016) Prevalence of mental health disorders in adult minority ethnic populations in England: A systematic review, London: EPPI-Centre, Social Science Research Unit, UCL Institute of Education, University College London.

Rose, D. and Pevalin, D.J. (eds) (2003) A researcher's guide to the National Statistics SocioEconomic Classification, London: Sage. doi: 10.4135/9780857024725

Royal College of Psychiatrists (2008) Mental health and work, London: Royal College of Psychiatrists and Health Work Wellbeing. Available at: https://assets. publishing.service.gov.uk/government/uploads/system/uploads/attachment_data/ file/212266/hwwb-mental-health-and-work.pdf.

Roza, S.J., Hofstra, M.B., van der Ende, J. andVerhulst, F.C. (2003) 'Stable prediction of mood and anxiety disorders based on behavioral and emotional problems in childhood: A 14-year follow-up during childhood, adolescence, and young adulthood', American Journal of Psychiatry, 160(12): 2116-21. doi: 10.1176/appi. ajp.160.12.2116

Rubin, D.B. (1987) Multiple imputation for nonresponse in surveys, New York: Wiley. doi: 10.1002/9780470316696

Schoon, I. and Bynner, J. (2019) 'Young people and the Great Recession:Variations in the school-to-work transition in Europe and the United States', Longitudinal and Life Course Studies, 10(2): 153-73.

Stevenson, D. and Farmer, P. (2017) Thriving at work: The Stevenson/Farmer review of mental health and employers, Independent Review of Mental Health and Employers, London: HM Government. Available at: https://assets.publishing.service.gov.uk/ government/uploads/system/uploads/attachment_data/file/658145/thriving-atwork-stevenson-farmer-review.pdf.

Werneke, U., Goldberg, D.P., Yalcin, I. and Ustün, B.T. (2000) 'The stability of the factor structure of the General Health Questionnaire', Psychological Medicine, 30(4): 23-9. doi: 10.1017/S003329179900135X

Winefield, A.H. (1995) 'Unemployment: Its psychological costs', in C.L. Cooper and I.T. Robertson (eds) International review of industrial and organizational psychology, Vol. 10, Chichester:Wiley, pp 169-212.

Wittchen, H.U. and Jacobi, F. (2005) 'Size and burden of mental disorders in Europe: A critical review and appraisal of 27 studies', European Neuropsychopharmacology, 15(4): 357-76. doi: 10.1016/j.euroneuro.2005.04.012

World Health Organization (2013) 'Nutrition, topics, background 2.1: The global burden of chronic'.Available at: www.who.int/nutrition/topics/2_background/en/.

World Health Organization (2014) 'Mental health: A state of well-being'. Available at: www.who.int/features/factfiles/mental_health/en/.

World Health Organization (2015) 'The European Mental Health Action Plan 2013-2020'.Available at:www.euro.who.int/_data/assets/pdf_file/0020/280604/ WHO-Europe-Mental-Health-Acion-Plan-2013-2020.pdf. 